\title{
Are Background Feelings Intentional Feelings?
}

\author{
Emilia Barile \\ Department of Philosophy, University "Vita-Salute”, Milano, Italy \\ Email: emiliabarile@virgilio.it
}

Received 7 September 2014; revised 28 September 2014; accepted 8 October 2014

Copyright (C) 2014 by author and Scientific Research Publishing Inc.

This work is licensed under the Creative Commons Attribution International License (CC BY). http://creativecommons.org/licenses/by/4.0/

(c) (7) Open Access

\begin{abstract}
I address the problem of the intentionality of "feeling", considering the study-case of "background feelings" (malaise, tension, etc.) in Damasio $(2003,2010)$. Background feelings, in fact, are "border case" feelings: These feelings seem lacking intentionality, at least by the meaning that their intentional content is not any object in the world they refer to. Differently from other feelings connected to intentional states (such as emotions, for ex., feelings are mainly considered arising from), background feelings reveal a bodily nature of feeling at its core, while intentionality of feelings, when any, rather depends on the intentionality of the states feelings concern. Background feelings reveal an intimate, immediate relation to our own body we can't catch considering feelings always and only connected to emotions. The intimate relation to the body, coming in "foreground" in these feelings only, should shed more light on another key feature of feelings, namely their phenomenality, more than their "supposed" intentionality.
\end{abstract}

\section{Keywords}

Feelings, Emotion, Intentionality, Bodily Self, Damasio, Phenomenal Consciousness

\section{Introduction}

To this day we do not have a shared taxonomy nor a definition of feeling, agreed upon neither among nor within the various disciplines contributing to the so-called "affective science". Each approach even employs the same term "feeling" in order to refer to very different phenomena. It may not be expected that the various disciplines contributing to an affective "science" (by the meaning of "rigorous analysis") such as psychology, neuroscience, philosophy, comparative literature, cultural anthropology, sociology, and history agree on jointly accepted definitions. Worse, however, is that even within neuroscience, within psychology, and within philosophy, etc. there is no general agreement on how to classify and define feelings, emotions or other related affective phenomena. 
We encounter as many classifications and definitions of "feeling” or of "emotion" as theoretical perspectives. In order to bypass this difficulty, claiming explicitly what is understood as "feeling" or "emotion" time by time is necessarily required, but even this move should be not enough.

In literature, the label "feeling" is mostly connected to emotions. It may be useful, rather, acknowledging that "feeling" has a wider extent: We can feel a broader collection of states such as pains, itches, needs, desires and motivations. Moreover, in the philosophical texts-especially in the English language-the words "emotion" and "feeling" are even usually used as synonyms, which is misleading, because not every felt state arises from an emotion. De Sousa, for ex., recognizes not only similarities between emotions and feelings, but also important differences. In particular, he considers the case of the so-called "epistemic feelings"-feelings involved in inquiry, knowledge and metacognition: These feelings can be attributed also to sub-personal levels (while emotions occur at a personal level) and they usually are less complex than "full-fledged" emotions (De Sousa, 2009: 140). The term "feeling" thus includes a broader array of possible felt states: Emotion is only one of them, neither the more interesting one, I guess. Even if in a common-sensical and somehow metaphorical way, in everyday language too "feeling" is in fact used in a broader extent: Above all in the English language, people frequently say "I feel good" with reference to health, or they can say "I feel that" when someone touches them, or when they have a pain. Sometimes people also say "my feeling is that $p$ " to mean "my opinion is that $p$ ". Even by a superficial, previous linguistic analysis, then, we should understand something remarkable about feeling. We might ask, for instance, why we usually report of "feeling" only of certain kinds of states, but not of others. In a pregnant analysis of the case of needs as "felt" states, Castelfranchi has rightly pointed out that we usually say, for ex.: "I feel the need for...", "I feel the desire of..." or "I feel the motivation to...", but we don't say "I feel the intention of..." or "I feel the belief of..." (Castelfranchi, 1998: 56-57). What do states we report feeling really have in common? According to him, we do not report feeling (and probably we can't feel at all) those states exhibiting a stronger cognitive structure-such as intentions or beliefs: They all show no manifest perceptual, sensori-motoric components. "Feeling", whereas, seems subsuming only kinds of states connected to the body in a more intimate and direct way.

Really, feeling is a misty, or, at least a polysemic word: That's why I suggest using here the word feeling in order to refer to the entire array of possible felt states, including emotions, of course, but also to many other phenomena, e.g. pains, itches, needs, motivations, desires. My general questions, thus, are: What does it mean, in general, feeling anything? What is required that certain state or processes can be "felt" and others cannot?

In order to answer these questions, we will take into account mostly Damasio's approach because he offers a neuroscientifical description of both emotions and feelings, providing interesting remarks on the fundamental role of the body. He particularly stresses the role of the so-called "background feelings"-kinds of feelings clearly revealing an immediate, intimate connection to the body. We usually are not able to recognize such an evident relation to our own body in feelings of intentional states like emotions, for ex.: These feelings always refer to some object or event-specific or a-specific - in the world they are mostly focused on. In feeling arising from emotions, in fact, the body remains "unattended", both psychologically and, so to say, theoretically. Whereas, background feelings - such us "tension" or "malaise", for ex.-or other a-specific processes such as "moods" (background feelings differ from, even if they are connected to in a very intimate way) reveal an immediate, unique relation to our own body. We usually can't qualify this immediate access to the body than metaphorically or in negative terms (as "non-linguistic", "non-propositional”) or using "proto" adjectives, such as "pre-reflective", "pre-conscious" and so on. The general aim of this paper is contributing to pave the way towards a possible definition also in positive terms about the relation to our own body that feelings-above all background feelings - reveal: The strategy adopted here is considering questionable the main view on feeling, that is generally oriented in recognizing its intentional feature. My intuition is that if we consider feeling always and only as connected to emotions and also as being an intentional state itself (as emotions are mainly supposed to be), we will hardly be able to understand what is this kind of "immediate" access to our own body, feelings—especially background feelings—-nevertheless reveal.

\section{Mirroring Background Emotions}

Damasio introduces the concept of “background feeling” in Descartes' Error. By this notion, he wants to stress the intrinsic bodily nature of this specific kind of feeling: "I am postulating another variety of feeling which I suspect preceded the others in evolution. I call it background feeling because it originates in 'background' body 
states rather than in emotional states” (Damasio, 1994: 150). Background feelings do not develop from proper ${ }^{1}$ emotions but from basic body states, from those collections of bodily changes Damasio christens "background emotions". In this respect, it might be helpful to see background emotions and feelings in a mirror relationship to each other. The neurobiologist even uses more or less the same vocabulary in order to define both emotions and feelings at the background level:

When we sense that a person is "tense" or "edgy", "discouraged" or "enthusiastic", "down" or "cheerful", without a single word having been spoken to translate any of those possible states, we are detecting background emotions (Damasio, 1999: 52; my emphasis).

Prominent background feelings include: Fatigue; energy; excitement; wellness; sickness; tension; relaxation; surging; dragging; stability; balance; imbalance; harmony; discord. The relation between background feelings and moods is intimate: Drives express themselves directly in background emotions and we eventually become aware of their existence by means of background feelings (Damasio, 1999: 286; my emphasis).

Background feelings/emotions are not ordinary notions we share in our conceptual armoire: On account of background feelings arise from the awareness of the correspondent "background emotions", a preliminary clarification of these concepts and of the related taxonomy is here required, without aiming to provide an exhaustive view on the endless emotion-debate still going on nowadays ${ }^{2}$. The classification of emotions proposed by Damasio, in fact, is only one among several others: Each taxonomy implies a different interpretation of what we do mean by "emotion" or, rather, how we do understand each distinct emotion. Strictly speaking, in fact, we would have to deal with every single emotion in a different way because, also by a neurophysiological point of view, each emotion involves different neural patterns: Research on the so-called "basic" emotions (Ekman, 2003), for ex., shows that, at least fear and disgust are realized by different neural pathways (see Panksepp, 1998). Nevertheless, summarizing, we might say that neurobiological literature (e.g. LeDoux, 1996; Damasio, 1999, 2010) usually backdates the emergence and the existence of emotions to less evolved beings, while cognitive theories (e.g. Nussbaum, 2001; Ortony et al., 1988; Frijda, 1986) support a more anthropocentric view. The different approaches to emotion mainly debate among the particular relevance of both the bodily and the cognitive dimension, and their mutual relationship.

Opposite to the dominant cognitive paradigm, Damasio regards emotions, especially at the most basic level, essentially as collections of bodily rather than cognitive states. In this respect, he follows the steps of the James-Lange theory of emotions (James, 1884; Lange, 1885). Damasio thus distinguishes three levels of emotional processes, according to their degree of complexity and evolutionary heritage: The so-called "background emotions"-complex collections of bodily changes, basic homeostatic processes, pain and pleasure behaviours; "primary" or (supposed) universal "emotions"-joy, sorrow, fear, anger, disgust, surprise; and, eventually, "secondary" or social "emotions": Compassion, shame, guilt, pride, jealousy, envy, gratitude, admiration, contempt, etc. We can generally differentiate emotions by their increasing degree of complexity: The emotions of higher complexity (e.g. secondary emotions) are installed on the previous ones (e.g. primary emotions), thereby integrating and increasing lower level capacities, by using their neural pathways and anatomical components. Secondary emotions are shaped more by cognitive aspects: Their expression and communication depend more on social and cultural influences than those of primary emotions, which are shared by different cultures and even species (Darwin, 1872; Ekman, 2003). Additionally, the brain systems as well as the other bodily systems underpinning different kinds of emotions are incorporated, both ontogenetically and phylogenetically.

Whereas many other approaches to affective phenomena might converge on the distinction between what Damasio calls "primary" and "secondary" emotions, "background" emotions are less recognized thus far. Background emotions subsume states such as enthusiasm, wellness, malaise, excitement, tension, edginess, relaxation, tranquility, etc.

When I developed this notion ${ }^{3}$, I began seeing background emotions as the consequence of deploying certain combinations of the simpler regulatory reactions (e.g. basic homeostatic processes, pain and pleasure behaviors, and appetites), according to the nesting principle noted earlier. Background emotions are composite expressions of those regulatory actions as they unfold and intersect moment by moment in our lives. [...] These include metabolic adjustments associated with whatever internal need is arising or has just been satisfied; and with

\footnotetext{
${ }^{1}$ What Damasio calls “primary” or "secondary” emotions.

${ }^{2}$ I already proposed a more detailed reconstruction of this debate in 2010. About that, see also Deonna \& Teroni, The Emotions: A philosophical introduction, Routledge 2012.

${ }^{3}$ Here Damasio refers to his Descartes' Error (1994) [NoA.].
} 
whatever external situation is now being appraised and handled by other emotions, appetites, or intellectual calculation. The ever-changing result of this cauldron of interactions is our "state of being", good, bad, or somewhere in-between. When asked "how we feel", we consult this "state of being" and answer accordingly (Damasio, 2003: 44).

Damasio regards all three kinds of emotions as indexes of regulatory mechanisms, but with different triggers and targets: Background emotions are more complex processes than drives, biological motivations and other bodily changes, but less complex than proper emotions. He offers the following taxonomy of mechanisms involved in regulating life, ordered by their degree of complexity:

-Secondary or social emotions;

-primary emotions;

-background emotions;

-drives and biological motivations;

-pain/pleasure behaviours (withdrawal/approach);

-immune responses;

-basic reflexes;

-metabolic regulation (Damasio, 2003: 31-34).

Therefore, background emotions are understood as combinations of simpler regulatory reactions (bodily changes) such as homeostatic processes, pain/pleasure behaviours, etc., with drives, motivations, pain and pleasure as their triggers or constituents - but they are more complex than these processes, which all contribute to regulating life.

In order to understand the distinctive features of background emotions we might distinguish them from the other non emotional regulatory responses. If it suffices to define particularly background emotions as nothing but complex collections of bodily changes, we might ask in what sense they differ, for instance, from other metabolic regulation processes or immune responses. Damasio invokes the background emotions' higher degree of complexity, without providing any further detail. But this move is not very convincing because, by his own criteria, also immune responses should be considered as kinds of proto-emotional states: Immune responses too, in fact, are "more complex" than, for ex., metabolic regulation processes. At first, background emotions might look the same as moods, rather, and their connection, indeed, is intimate: Background emotions contribute to build up the (neural and behavioural) configurations identified with "moods" at a reflective level. But moods and background emotions differ, for ex., in that background emotions reveal the temporary, "on-line" inner situation of the organism — while moods are long term processes — and in the sharper identification of the stimulus (Damasio, 2010: 125). We can get up in the morning, for instance, feeling in "a very good mood", going on the whole day, but this does not mean that we could not also have rather bad background emotions such as "tension" or "malaise" for short periods of time during the same day. If we are not affected by mood disorders, we usually don't change a "good mood" immediately due to minor disturbances such as a short tension or malaise, provided that the duration of these background emotions is short enough and they do not occur too often, of course.

Furthermore, in qualifying this kind of "proto-emotions"4 as "background emotions", Damasio stresses particular features: First of all, "background" means that the involved processes occur in our body, even when we are not aware of them and when they are not in the focus of our attention. Secondly, background emotions are distinguishable from "unconscious"-repressed-states (in a Freudian sense) since we can become aware of them whenever we direct our attention towards them. Thirdly, "background" means a-specific or objectless, a shared feature with states like moods, but a distinguishable feature from "proper" emotions, that usually concern specific objects or situations. When compared to proper emotions, further differences are that the "source" of background emotions is rather internal than external, and that they are less expressed by facial expressions and action tendencies than do "conventional" emotions (Damasio, 1999: 53; 342). By the way, as I already reported (Barile, 2010), this concept by Damasio is not completely original defined this way: In fact, "background emotions"-above all at the corresponding reflective level of background feelings-are similar to "vitality affects", already proposed by Stern (1985) and renamed as "forms of vitality" in Stern 2010. As Damasio himself recognizes, background feelings were identified even before also by Langer $(1942)^{5}$, a Whitehead's disciple (Damasio, 1999: 287). Additionally, something similar to the concept of "background emotion" in the stratification of affective states was already attested in Scheler $(1913,1916)$, particularly at the level of Lebensgefuehlen ${ }^{6}$.

${ }^{4}$ I would rather say "proto-emotions" since they might lack intentionality, as I will try to show later on in the paper.

${ }^{5}$ Damasiodidn't realize this fact in the first book (1994) where he introduced the concept of background emotion.

${ }^{6}$ Thanks to De Monticelli and Caminada’s suggestions, I already underlined this parallel in lexicon and in concepts in Barile 2010. 
Prima facie, the "extra" level of the so-called background emotions—-we should distinguish both from emotions proper and from non-emotional, mere regulatory processes-rather seems to overcomplicate a possible taxonomy of emotions than simplifying it. This taxonomy is already rich and problematic enough: Ockham's razor might easily shave off this further level of "background" emotions. Nevertheless, the background dimension of these "emotions" is very useful in order to understand what background feelings are, rather. Background feelings are as unrecognized concepts as background emotions: These feelings do not arise from proper emotions as all the other feelings do, but they follow directly those complex collections of bodily changes Damasio christens "background emotions". Background feelings, in fact, are just felt—aware—background emotions (Damasio, 1999: 286). These "proto-emotions" cannot be considered emotions proper: Rather, "the background feeling is our image of the body landscape when it is not shaken by emotion" (Damasio, 1994: 150-151; my emphasis).

\section{3. "Background Feelings": A Definition}

Damasio introduces the further level of "background" feelings so to stress the role of lower background bodily states (especially these feelings arise from). This view is completely different from the denotation of feelings as "high order" mental states ${ }^{7}$. Traditionally, in fact, we understand feelings as subjective, inner experiences (phenomenal) and, more recently ${ }^{8}$, as intentional states too, above all those feelings following emotions. Opposite to this view, Damasio stresses the fundamental role of the bodily dimension that is evident especially in feelings not originating in proper emotion, such as background feelings.

Background feelings indicate the temporary inner "temperature" of the organism. What we feel are not discrete bodily changes as such, but more complex states, such as "wellness", "relaxation" or "tension": These are indexes of the condition of the body as a whole, perceptions, resulting at a reflective level from the awareness of the complex collection of bodily changes (the so-called "background emotions").

It is probably correct to say that background feelings are a faithful index of momentary parameters of inner organism state. The core ingredients of that index are: 1) The temporal and spatial shape of the operations of the smooth musculature in blood vessels and varied organs, and the striated muscle of heart and chest; 2) the chemical profile of the milieu close to all these muscles fibers; and 3) the presence or absence of a chemical profile signifying either a threat to the integrity of living tissues or conditions of optimal homeostasis ${ }^{9}$ (Damasio, 1999: 286-287).

The role of the body is hence fundamental: The representation of the body ${ }^{10}$ is always there, even if out of the attentional focus or unaware - which is, by the way, one of the meanings of "background". This representation of the present, "on-line" state of the body, as it changes at any one time, originates in cortical sites (sensory-motor cortical maps, topographically organized by signals coming from muscles) and on non-mapped sub-cortical sites, receiving signals from the viscera. The representation of the "potential" state of the body, whereas, results from proprioception and interoception (see Cameron et al., 2002). I intend here "proprioception" in the narrow sense, as the perception of muscles and skeletal structure, feeding back the sense of the position of the body in the environment, whereas interoception is the perception of the internal milieu and signals coming from viscera, concerning the sense of the homeostatic balance of the organism ${ }^{11}$. The result of all of these bodily

\footnotetext{
7"Feeling” has been used in Western philosophy so to refer to mental states that, contrary to thoughts, have a rather vague content (see the entry "Gefühl” in the Historisches Wörterbuch der Philosophie).

${ }^{8}$ I refer here to the contemporary debate on intentionality of bodily feelings I'm dealing with in the next paragraph.

${ }^{9}$ Experimental evidences of the existence of this kind of feelings are shown in such cases as asomatognosia and phantom limbs: Sufferers, in fact, exhibit an inhability to reach those very background states via "on-line" informations about the present state of the body (see also Damasio, 2003: 192-193).

${ }^{10}$ In Damasio the concept of "representation" is very equivocal: It is sometimes even used in a very commonsensical way, as I already pointed out in a previous paper in Barile 2009. In neuroscience, the expression "neural representation”, for ex., usually refers to a complex neural pattern with a specific content: But this expression is oxymoronic in that the concept of "representation", at least in the standard meaning, historically has been introduced so to indicate a theoretical entity other or more than the underlying neural pattern. Differently from neural configurations, in fact, we can't observe representations themselves, but we have to suppose their existence in order to explain (supposed irreducible) "mental" states, that cannot be simply described in terms of "neural patterns": In standard cognitive approaches neural patterns are simply considered "not enough” (see Anderson 1980 and RTM models).

${ }^{11}$ In literature, interoception and proprioception are almost considered as the same phenomenon also because they can be separated just in a theoretical analysis, but they usually—-that is, in non-psychotic cases-occur together: In particular, the role of interoception proper is mainly neglected. As many others (see, for ex., Tsakiris \& Fotopoulou, 2008; Tsakiris, Schütz-Bosbach, \& Gallagher, 2007), also Gallagher, in his seminal book How the Body Shapes the Mind (2005), considers proprioception mainly, while the role of interoception proper is underestimated, at least. Although he discusses several meanings of "body perception" and even if he does not completely ignore other pre-noetic aspects, such as the role of the physiological dimension, nevertheless, most of his analysis in the book deals with proprioception and kinesthesia (see Ch. 6, 149 ff.).
} 
feedbacks is the sense of the body as a whole, which is always present, at least on the background, until we focus our attention on it.

Years ago I called attention to one of these groups and gave it a name: background emotions. Examples include enthusiasm and discouragement, two [background] emotions that can be prompted by a variety of factual circumstances in one's life but also brought on by internal states such as disease and fatigue. Even more than with other emotions, the emotionally competent stimulus of background emotions may operate covertly, triggering an emotion without one's being aware of its presence. Reflection on a situation that has already happened, or consideration of a situation that is a mere possibility, can trigger such emotions. The resulting background feelings are just a small step up from primordial feelings ${ }^{12}$ (Damasio, 2010: 125).

Feelings usually involve some feedbacks from the body: They are somehow connected to bodily changes such as homeostatic processes, simple reflexes, physiological reactions, autonomic responses, or hormonal changes. Even in case of feelings that seem quite far from a characterization in bodily terms, such as the so-called "epistemic feelings" analyzed by De Sousa (2009)—i.e. the "feeling of knowing", the "feeling of rightness", the "feeling of doubt", etc.-an influence of bodily modifications is recognized at the neurotransmitters level. It is attested a role for acetylcholine and norepinephrine for "feeling of uncertainty" (Yu \& Dayan, 2005), of oxytocin for the "feeling of trust" (Kosfeld et al., 2005), of drug as Prozac (Kramer, 1993) in regulating the "feeling of certainty" in OCD (Obsessive Compulsive Disorders). These bodily changes all occur at the sub-personal, implicit level of feelings, enabling explicit inferences or beliefs at the full light of awareness. Even if De Sousa himself recognizes that we have not to exaggerate the causal role of neuromodulators (De Sousa, 2009: $148 \mathrm{ff}$.), nevertheless he maintains: "we seem to see into the very point where physiological process and subjective feelings coincide” (De Sousa, 2009: 147).

Another possible counter-example of the role of bodily features in feelings might come from accounts concerning feelings of the so-called "secondary emotions", such as the case of the "feeling of guilt" (see Gilbert, 2002). In Gilbert's approach, judgments, beliefs and commitments are constitutive features, while "pangs" or "twinges" associated to guilt feelings are concomitant states only: That pangs and twinges might be hold as necessary conditions of guilt feelings is, for Gilbert, arguably at least. Nevertheless, the argument at issue in his paper is demonstrating the existence of collective guilt feelings as distinguished by mere membership's guilt feelings, interpreted in terms of the collection of their members' individual feelings. According to him, a "collective" is the plural subject of a joint committed action that is judged as "wrong"-in the case of the feeling of guilt-by the members of the group. His theoretical target, thus, is building up a notion of "collective" as different from the mere sum of the individuals: In true collectives, individuals are jointly committed, in the sense that this commitment can't be split as unilaterally as a personal one. The commitment is foundational for the group itself and it gives the authorization for a collective action, even if each member of the group does not directly perform this action. Gilbert, in fact, does not deny that, at an individual level, there are pangs and twinges, responsible of the phenomenology of personal guilt feelings (Gilbert, 2002: 141-142). His argument is that collective and personal guilt are indistinguishable just by means of concomitant pangs and twinges (Gilbert, 2002: 135): The distinctive features are, thus, judgments and thoughts, rather. Nevertheless, in my view, the example of collective feeling arising from secondary emotions, such as the "feeling of guilt", is not a counter-example for the constitutive role of the bodily dimension in individual feelings too. Gilbert's emphasis about judgments and beliefs as constituents of feelings might be traced back to the same structure of the "secondary emotions" these feelings follow, that are more shaped by cognitive aspects: His view is based on the "plausibility" he concedes to cognitive approaches to emotions (Nussbaum ${ }^{13}$, 2001; Schaffer, 1983).

In my view, feelings rather show an immediate and intimate connection to the body that is not so evident in other mental states that are strongly cognitively structured, such as intentions, judgments, beliefs, etc. This does not necessarily imply that there is no bodily component involved in the so-called "conceptual thought", but just that this connection to the body is not so manifest: If so, in fact, there would be an inexplicable evolutionary gap

\footnotetext{
${ }^{12}$ I amdealing with the further level of primordial feelings later on in this paragraph.

${ }^{13}$ Nussabaum's example reported in Gilbert's paper considers also the case of a so-called "primary emotions" as anger, in the case of "asymptomatic anger”: "my anger (...) is at times entirely asymptomatic (...) [it does not have] the phenomenology of 'boiling' so many people report" (Nussbaum, 2001: 61). According to Nussbaum's and other cognitive approaches, emotions are forms of evaluative judgements (Nussbaum, 2001: 22). We might reply that she is dealing with emotion again here, not with "feelings". Secondly, it is not that clear if "asymptomatic anger" is, rather, just a recall of the anger occurred at that time, and what is the difference about "thinking" and "feeling" anger itself (I already provided a deeper analysis of the differences between cognitive and neuroscientifical approaches to emotions in Barile, 2009).
} 
that would need for more clarification and that, by the way, is not at issue in this paper ${ }^{14}$. We might say, metaphorically, that some feelings go over the "border", "out" (in the world), and the body is in the background, while others are "inside" - that are bodily feelings. We might shift attention from the body to the world and vice versa, depending on which kind of feelings we are dealing with. By the way, it seems that there are no emotional feelings that are not bodily. Nevertheless, as also Goldie underlines, feelings are neither simply bodily changes, nor perceptions of bodily modifications "as such" (Goldie, 2002: 237, note 7): We neither perceive homeostatic processes themselves, nor hormonal changes, which are unaware, automatic responses. What we perceive, rather-what we are aware of -is that "something" is happening with us, i.e. in our body (be it considered as a whole or as some specific part of it). Nevertheless, bodily changes and bodily feelings are not always connected: Bodily changes occur unaware most of the time, but we can just sometimes become aware of the resulting state of the body by means of bodily feelings. Hence, whenever we feel something, it refers to something changing in the body —not necessarily something we are aware of, however. The passivity of feeling experience hints us: Feelings just "happen" to us.

On this point, Gallagher would rather say that what we perceive (what we are aware of) may be the world (Gallagher, 2005), or a math problem, or another person, etc. Adopting a so-called "adverbial theory" of emotions/feelings, he rather maintains that we sadly, joyfully, jealously, etc. perceive the world, problems, others, etc. We do not perceive the body and then, on that basis, decide how we feel. We may angrily perceive the world without even knowing that we are angry (someone else may point that out to us): By the way, this is what he understands as "pre-noetic”. In Gallagher's view, bodily states or processes condition, or color, or shape the way we perceive things, but those states or processes are not themselves the objects of our perception. When we do become aware that "something is happening with us" it is usually after the fact, in reflective awareness. Nevertheless, as many other philosophical approaches, Gallagher too considers feeling as "attached" to the emotions: Furthermore, I will analyze the body/world relation here at issue in the next paragraph.

Damasio's background feelings, whereas - that do not arise from emotion proper-can also concern the sense of the body as a whole only, not of the world ${ }^{15}$ : This is much clearer when we consider the more primitive level of the so-called "primordial feeling" he recently introduced (Damasio, 2010), background feelings are just a small "step up".

There is some deeper feeling to be guessed and then found in the depths of the conscious mind. It is the feeling that my own body exists, and it is present, independently of any object with which it interacts, as a rock-solid, wordless affirmation that I am alive. This fundamental feeling, which I had not deemed necessary to note in earlier approaches to this problem, I now introduce as a critical element of the self process. I call it primordial feeling, and I note that it has a definite quality, a valence, somewhere along the pleasure-to-pain range. It is the primitive behind all feelings of emotion and therefore is the basis of all feelings caused by interactions between objects and organism (Damasio, 2010: 185; my emphases).

Damasio recognizes that, in essence, his definition of "primordial feelings" can be traced back to Panksepp (1998), i.e. to the notion of "early feelings", even with some differences ${ }^{16}$. "Primordial feelings" and "early feelings" share that primordial feelings precede any interactions with the world or any feeling arising from emotions $^{17}$. In his Self Comes to Mind (2010), Damasio also provides a deeper analyses of the relation between "primordial feelings" and "background feelings". The "feeling of existence", the feeling of being "alive”, pri-

\footnotetext{
${ }^{14}$ Stocker too calls against the so-called "ethical cognitivism" and considers, rather, that "judgements, questions (...) can be taken as essentially involving feelings" (Stocker, 1983: 22), and not the reverse. He deals with specific kinds of feelings such as "care”, "interest” and "concern" that are irreducible "psychic" feelings, as opposed to the feelings of emotions. These "psychic" feelings constitute, rather, "modes" of action, desire, reason and so on.

${ }^{15}$ See the study cases of "tension”/“relaxation” in the last paragraph.

16“'Panksepp's views differ in the following ways. First, the simple feeling that he posits appears to be necessarily related to external events in the world. He describes it as 'that ineffable feeling of experiencing oneself as an active agent in the perceived events of the world'. (...) In theory, primordial feelings occur regardless of whether the protoselfis engaged by objects and events external to the brain. They need to be related to the living body and nothing else. (...) Second, Panksepp relates this primary consciousness mainly to motor activities in structures of the brain stem (periaqueductal gray, cerebellum, superior colliculi), while I place the emphasis in sensory structures such as nucleus tractussolitarius and parabrachial nucleus, albeit in close association with the periaqueductal gray and deep layers of superior colliculi" (Damasio, 2010: ch. 1, note 17; my emphases).

${ }^{17}$ Damasio provides quite incoherent versions for that: He maintains later on in the same book that "as stated in note 17 of Chapter 1, Panksepp also gives emphasis to the notion of early feelings, without which the process of consciousness cannot proceed. The detailed mechanism is not the same, but I believe the essence of the idea is. More often than not, treatments of feeling assume that they arise from interactions with the world (as in James's 'feelings of knowing' or my 'feeling of what happens') or as a result of emotions. But primordial feelings precede those situations, and presumably Panksepp’s early feelings do too” (Damasio: 2010, ch. 8, note 3).
} 
mordial feelings feed back as the "sense of the body", arises from several different bodily feedbacks—changing all over the time-and from interoceptive and proprioceptive more stable maps of the body as a whole. Background feelings occur at a reflective level, feeding back the "on-line” representation of the state of the body, updated at any one time. Opposite to Gallagher's view, when asked "how do you feel?” we consult our internal state of the body as a whole - that is continuously updated-and answer accordingly (Damasio: 1994: 150-152). We usually do not focus our attention on that (this is, incidentally, one of the main distinctive features of "background" phenomena) when involved in relations to the objects or other people in the world-as in emotions, for ex. The sense of the body is a continuum whose absence or fragmentation in the several dimensions constituting what is intended as "me" 18 _from the lowest possible biological meaning to the most cognitively elaborate narrative reports-suddenly and dramatically comes in "foreground" when this sense is disrupted (see Tsakiris, Prabhu, \& Haggard, 2006; Sacks, 1987). Both primordial and background feelings are bodily feelings that are not "attached" to emotions proper: Might we consider these feelings intentional too? In which sense, if so?

\section{Feelings and Intentionality}

I will take into account here Goldie’s and Ratcliffe's approach to feeling: Both of them, in fact, share the theoretical effort of explaining how the bodily feature of feelings can be held together with the intentionality of the states feelings concern, such as emotions - that are mostly referred to something in the world. In the last section of the paper, whereas, I will take into account again Damasio's approach. Differently from these and other theorists, in fact, he stresses the role of background feelings: These feelings are specific kinds of (bodily) feelings arising not from emotions, but from bodily states or, better, from that cauldron of bodily changes he christens "background emotions" - that are not "emotions" proper. As I will try to show in the following, differently from emotional bodily feelings, we can consider background feelings-and, above all, the recently introduced primordial feelings they develop from- "border case” feelings, lacking intentionality, at least in the sense that they might also lack the intentional reference to anything in the world. If so, we might consider these feelings as counter-examples of the "supposed" intentionality of bodily feelings: Furthermore, this should also let us reconsider the "nature” of feeling itself. At least in Damasio’s view, in fact, we can regard background feelings not only as specific kinds of bodily feelings, but also as the evolutive forerunners of all kinds of feelings (Damasio, 1994: 150).

Before jumping to these conclusions I will try to reach in the next paragraphs, a previous discussion on intentionality is here required: Most of the theoretical problems connected to this issue, in fact, depends on how we do understand intentionality at any one time. In the contemporary debate about the intentionality of "bodily" feelings in emotional experience (see Slaby \& Stephan, 2008; Slaby, 2007; Ratcliffe, 2005; Ben-Ze’ev, 2004; Goldie, 2002), the intentional feature of feeling is understood, in fact, in very different ways. Intentionality is (standardly) conceived as a structural relationship between a mental state or process, on the one hand, and something this state or process is about or refers to, on the other (Brentano, 1874) ${ }^{19}$. What mental states or processes are about or refer to often are specific objects, properties or events. Nevertheless, as Slaby \& Stephan (2008) outline, there are also mental states that are not about specific objects, but that we can still consider intentional, though in a non-standard way. These kinds of states comprise, for instance, “moods”, objectless emotions like "anxiety” and, in general, all background feelings. Among them we can recognize, in particular, the so-called existential feelings recently conceptualized by Ratcliffe as "background (...) relationship [s] to the world” (Ratcliffe, 2005: 45).

Existential feelings have been neglected by research on emotions for a long time: More particularly, they are defined as "ways of finding oneself in a world” (Ratcliffe, 2005: 50). Examples of this kind of feelings are, e.g. feeling “complete”, “flawed and diminished”, “unworthy”, “humble”, “separate and in limitation”, “at home”, “a

\footnotetext{
18“"The me includes: (1) the perspective in which the objects are being mapped (the fact that my mind has a standpoint of viewing, touching, hearing, and so on, and that the standpoint is my body); (2) the feeling that the objects are being represented in a mind belonging to me and to no one else (ownership); (3) the feeling that I have agency relative to the objects and that the actions being carried out by my body are commanded by my mind; and (4) primordial feelings, which signify the existence of my living body independently of how objects engage it or not. The aggregate of elements (1) through (4) constitutes a self in its simple version” (Damasio, 2010: 185; my emphases).

${ }^{19}$ Here I deal with the so-called "third thesis" by Brentano, considering intentionality as the "hallmark" of the mental, without necessarily being engaged also in the other two theses. Because Brentano’s view is very controversial, I consider here just this feature of his analysis that is more connected to the discussion proposed.
} 
fraud” (Ratcliffe, 2005: 45). The most relevant common features of existential feelings—as a specific group of (also "bodily"20) feelings-are that they are not only a-specific, objectless, but also primarily background orientations in shaping our experience of the world. According to us, then, following Ratcliffe's own definition, being objectless does not mean by itself being non-intentional. Of course, states as moods, objectless emotions, existential feelings and, in general, all background feelings are not intentional by the standard meaning, understood as referring to specific objects. More precisely, Ratcliffe (2012) defines existential feelings (as kinds of background feelings) "pre-intentional" rather than intentional themselves, i.e. as conditions of possibility of other intentional states. Nevertheless, in my view, we can still consider existential feelings intentional at least in the sense that they are always related to the world, that we experience as a whole. The "something" they relate to, in fact, is not a specific, well defined object, but the whole situation, environment, or life circumstances: When we are "not in the mood" it is the whole relation to the world-above all to the other people, for instance- that is compromised, and the same happens when we feel "unfamiliar" or "not at home". Thus, the core feature of intentionality by Ratcliffe seems to be not the specificity of particular objects or events, but the relationship to the world rather - even if it is the whole world, including myself in my relationships to the other persons or to the environment. The philosopher, in fact, never considers the body as a possible object of perception, but as just that through which we perceive objects.

In a similar effort of explaining how we can still consider "intentional" bodily feelings involved in emotions - which cannot be easily said to be about something-, Goldie (2002) understands bodily feelings as intentional states too (as soon as we conceive intentionality in a "broader" sense, namely in the sense of "directedness")—as being directed towards something: In this case, towards a given part of one's own body. This broader sense exceeds the standard meaning of intentionality as "aboutness" (i.e. as being about something) ${ }^{21}$. Furthermore, in order to explain in which way we can consider "bodily" feelings too as intentional, Goldie introduces a distinction between "bodily feelings" and "feelings towards", though in emotional experience these two kinds of feeling are always connected. "Bodily feelings" are feelings of the condition of the body, of the bodily changes (triggered from "inside"), while "feelings towards" are feelings towards the object of the emotion (triggered from "outside"). Following this distinction, we can consider both feelings as intentional, though in a different way. Feelings towards are intentional both in the sense of directedness (they are "directed" towards an object outside the body, in the world) and in the sense of aboutness (they are also "about" this object). Bodily feelings, whereas, are intentional in the sense of being directed towards the body (inside), but not of $a b$ outness - they are not themselves "about" anything in the world. The intentional content of bodily feelings is some part—localized—of the body, rather (by the way, I find this expression misleading: A bodily feeling is rather localized in some part of the body and not directed towards it) ${ }^{22}$. In Goldie's example of the hairs going up on the back of one's neck in the emotion of fear (Goldie, 2002: 235), he considers the feeling towards the object of fear properly intentional, because it is about the object of the emotion- "the lion", in this case, or something else in the world. Whereas, the bodily feeling, that is the feeling of the localized part of the neck where the hairs is going up on account of fear, is intentional in the sense of "directedness" only: This feeling is directed to a precise part of the body, that is the neck, but it is not "itself" about anything in the world. Bodily feelings show, thus, a kind of "borrowed intentionality",23: Nevertheless, what they borrow is the directedness to, but not the aboutness towards the world (Goldie, 2002: 247).

In contrast to Goldie, Ratcliffe claims that also bodily feelings are feelings towards the world considered as a whole, by means of the body (Ratcliffe, 2005: 47-48). In his phenomenological account, body and world are always intertwined, both inextricably and ontologically. They cannot exist separately: Bodily feelings, in fact, are in the body, while the body itself often remains unattended and unaware-in the background. At the same time, bodily feelings are, rather, "about" the world beyond the body — than about the body itself. Thus, the body is not the intentional content of bodily feelings, but it is that through which we keep the intrinsic relation to the world.

\footnotetext{
${ }^{20}$ Ratcliffe (2012) clarifies that existential feelings might be considered bodily as far as they comprehend more than just "feelings of the body"; the term "bodily feeling" is insensitive to a distinction between two kinds of bodily experience: The feeling body needs to be distinguished from the felt body. He considers existential feelings neither noetic nor noematic feelings, but just way of shaping the relation to the world.

${ }^{21}$ We might find the same distinction also in Searle, 1983.

${ }^{22}$ Thanks to A. Stephan and the Osnabrueck IKW Ph.D. students group for having noticed this while discussing with me the paper in their journal club meetings.

${ }^{23}$ Goldie further explained and developed this concept in Goldie, 2000.
} 
According to Ratcliffe, this is clearly revealed by the "model case" of touch, in which the relation between bodily feelings and the world is fully intertwined, because "to touch is to experience a relation between one's body and an object it comes into contact with” (Ratcliffe, 2005: 48). In line with Merleau-Ponty’s analysis of touching experience (Merleau-Ponty, 1945), Ratcliffe proposes also a detailed description of the phenomenology of feeling in touch. Additionally, he extends this explanation in terms of structural relatedness to the world to every kind of feeling experience.

In connect feeling dimension to emotions, both Goldie and Ratcliffe have to face the problem of how we can held the bodily dimension of feelings involved in emotions together with the intentionality of the states feelings concern. I follow here a different strategy: Taking into account Damasio's background feelings, that are specific kinds of feelings arising not from emotions (but from basic bodily states or, better, from that cauldron of bodily changes he christens "background emotions"- that are not emotions proper-), I wish to catch the core nature of feelings, independently (if so) from the intentionality of the states feelings are mostly related to. Background feelings (and certainly primordial feelings they develop from), in fact, seem lacking intentionality, at least in the sense that they might exist also without intentional reference to anything in the world. Background feelings are kinds of feeling in which the bodily dimension and the intentional one (in the sense of "reference to the world") are not necessarily connected: In my view, this fact might let us consider questionable that intentionality is part of the core structure of this kind of (bodily) feeling, at least. Far from being a critical point in Damasio's account, as many of his detractors have pointed out ${ }^{24}$ (that is a critical point for the case of emotions and other related intentional states only), I rather think that the background dimension of feeling the neuroscientist outlines reveals something that is more fundamental for a better understanding of the core nature of feeling in general. As kinds of feelings that may also have no intentional reference to the world, background feelings only might clearly reveal, so to say, the "pure" bodily nature of feeling, as I will try to show in the last section of the paper.

\section{Are Background Feelings Intentional Too?}

In this last section, I want to suggest the hypothesis that we might consider background feelings, as defined by Damasio, as counter-examples of the more recently claimed intentionality of bodily feelings (Slaby \& Stephan, 2008): Background feelings, in fact, seem lacking intentionality. In the following, I'll take into account again Goldie's, Ratcliffe's and others' understanding of intentionality and discuss whether it might be applied to background feelings too-as kinds of bodily feelings_-as conceptualized by Damasio, in order to exclude any meaning of intentionality (standard or broader) according to which background feelings might be considered intentional states themselves.

Let's be clear, first, about background feelings as understood by Damasio and Ratcliffe, because they share this concept only apparently. According to Damasio, the most distinctive meaning of "background" is that feelings of the background type allow us to experience our body in a very particular way, namely as a whole. Ratcliffe acknowledges background feelings as neurophysiological evidences for his own hypothesis of existential feelings (Ratcliffe, 2005: 52), he regards as kinds of background feelings. He also shares with Damasio the view that background feelings are a-specific and allow us experiencing things as "wholes". A closer look, however, reveals significant differences between background and existential feelings. Existential feelings as understood by Ratcliffe concern a relation to the world considered as a whole, while Damasio's background feelings might concern a relation to the body only as a whole, and not to the world ${ }^{25}$ - even if the body is in the world anyway, and it does not exist isolated, of course. This is even more evident in the previous level of "primordial feelings" background feelings develop from.

In order to understand better the difference between Damasio's and Ratcliffe's conception, let's analyze the process by which (firstly unfelt) background states of "relaxation" or "tension", for instance, might develop into background feelings of "relaxation" or "tension", where we might distinguish the following features:

-Our body can be in states of "tension" or "relaxation"- -states of the body as a whole, not of particular parts of it ${ }^{26}$;

\footnotetext{
${ }^{24}$ In his critique of Damasio's theory of emotions, Lenzen (2004: 302-307), for ex., points out that the neuroscientist does not take into account the intentional content of emotions, which is always something in the world, outside the body. Nevertheless, in Damasio's taxonomy of emotions and feelings at least background emotions/feelings really lack intentionality in this sense, because they can also be not referred to anything in the world.

${ }^{25}$ They might also have no relation at all to any object in the world, as Damasio himself acknowledges in his last Self Comes to Mind about the previous level of the so called "primordial feelings” background feelings are just a small "step up” (Damasio, 2010: 185).

${ }^{26}$ Consider that, even if you might localize this feeling in your shoulder, for ex., this does not mean that tension is arising from your shoulder or your foot or your hand only: The feeling of tension results from the condition of the body as a whole anyway.
} 
-we can perceive (become aware of) these states when we focus our attention on them: We can feel tense but, before noticing it, we simply are tense, as a "pure" bodily state permeating our being, our whole organism. Even when we do not focus our attention on these states, "tension”, e.g., is already in the background. Damasio would call such a state a "background emotion", not a background feeling yet;

-when we become aware of these complex collections ${ }^{27}$ of bodily states, we can sometimes correctly relate them to events in the world ("this tension is due to those unresolved conflicts"), we sometimes relate them wrongly to events in the world (false rationalizations), but some other times we are simply not able to see any connection between these collections of bodily states and any object or event-specific or a-specific-in the world;

-in the last case too we can still feel "relaxed" or "tense", as a "pure" bodily perception arising from the organism as a whole, even if we have no belief at all, no knowledge-that is, no intentionally structured stateabout possible connections between the corresponding bodily state and events in the world.

Let's be clearer on this point: Saying that "we are sometimes not able to see any connection between these kinds of states and the world" does not mean that background feelings are not caused by anything else, but that this "something" is not the intentional content of a representational activity connected to or constituting the feeling itself. In a more detailed analysis of the difference between "causes" and "reasons" presented in De Monticelli (2003: ch. 4, §3-4), she considers the case of “moods”-which, incidentally, background feelings are deeply related to, though background feelings refer to a different (on-line) temporal window and they have a sharper recognition of the stimulus. Moods usually are "groundless" states, in the sense that they have not a definite intentional content we can recognize as part of the structure of the feeling or mood itself, as in the case of feeling arising from emotions (e.g. feeling the fear "of” the lion). By the way, this does not imply that moodsor background feelings ${ }^{28}$ — are not connected to any "cause" they depend on.

Assuming for a while that all bodily feelings-background included-do have an intentional structure, nevertheless we would need for a clarification on what their content is. One answer might be that it is the body itself, rather than the world, in the cases described above: But Ratcliffe, for ex., considers this idea misleading. "Thus accounts of bodily feeling which assume that what is felt must be the body are mistaken. Existential feelings are bodily feelings that constitute the structure of one's relationship with the world as a whole” (Ratcliffe, 2005: 59). In his hypothesis of existential feelings as background relationships to the world that are bodily at their core, Ratcliffe distinguishes between a location in the body and what the feeling is related to-the world (Ratcliffe, 2005: 44). According to him, then, we cannot consider the body as the intentional content of the "bodily" feelings involved in emotions: The intentional content is always the world beyond, other than the body. The core difference between existential feelings and background feelings (in Damasio's sense), we guess, results from Ratcliffe's combination of Damasio's concept of background feeling with a phenomenological account, in which everything is completely intertwined in a structural (ontological) relationship to the world.

Accepting Ratcliffe's concept of existential feelings, Slaby \& Stephan (2008) also provide a detailed taxonomy of this kind of feelings, that is comprised of four levels:

-"Pure” (bodily) existential feelings: Feeling "alive”, “fresh”, “tired”, feeling "having” or "being a body”, etc.;

-“social” existential feelings: Feeling of “familiarity”/“unfamiliarity”, feeling of "security”, feeling "at home”, etc.;

-more "specific” existential feelings, conceptually more sophisticated and culture-dependent: General "anxiety”, feeling "invulnerable”, “vulnerable”, "lost”, "like a stranger”, “generally unwelcome”, etc.;

-“emotional” feelings: Feeling "flawed” or “diminished”, etc.

Following this more analytical taxonomy, Damasio’s background feelings would then belong to the first level. According to him, in fact, the sense of having or being a body arises at the level of the "primordial feelings" and of background feelings themselves, by providing the representation of the on-line state of the body. Ratcliffe recognizes that Damasio's background feelings comprise "the feeling of life itself, the sense of being” (Ratcliffe, 2005: 52); but the philosopher associates to Damasio's idea of “the feeling of being” rather "the sense of be-

\footnotetext{
${ }^{27}$ The integration into $a$ whole is not just a matter of awareness: Even at the previous level of "unfelt”, "unaware” background emotions we deal not with discrete bodily changes, such as hormonal level variations, for ex., but with the complex collection of bodily states, namely "wellness" or "enthusiasm”.

${ }^{28}$ De Monticelli (2003: ch. 3, §4) provides the same distinction also for Scheler’s Lebensgefuehlen, background feelings might be assimilated to.
} 
ing-in-a-world". According to Ratcliffe, in fact, the "feeling of being" concerns a relation to the world conceived as a whole. On the contrary, Damasio's background feelings, and above all the even more primitive level of primordial feelings such as the "feeling of existence", the feeling of being "alive" they develop from, concern the sense of the body as a whole only, not of the world (Damasio, 2010: 185). In Ratcliffe's view, Damasio is successful in both identifying background feelings as ways of structuring our experience of the world and in providing a neurophysiological theory of how this is realized, but he is wrong in not taking into account the possibility of background feelings having the world as their content. If we adopt Ratcliffe's account of intentionality, whose key feature is the structural relationship to the world, then, in my opinion, we cannot consider background feelings (in Damasio's sense) intentional: If background feelings have an intentional content, then this has to be the body itself, rather than the world.

Even adopting a broader account of intentionality for bodily feelings_as background feelings also arenamely that of “directedness” proposed by Goldie (2002), again Damasio's background feelings turn out to be not intentional. According to Goldie, in fact, intentionality of bodily feelings involved in emotions can be understood both in the sense of aboutness and in the sense of directedness, but in a quite different way. If we conceive intentionality of bodily feelings in the sense of their being "directed" to some parts in particular (localized) of the body, as Goldie claims, then background feelings - that are kinds of bodily feelings too- cannot be considered intentional in this sense. There is, in fact, no defined part, localized in the body, background feelings are directed to, but these feelings are bodily in the sense that they result from the sense of the body as a whole. Differently from what happens in emotional experiences, involving other kinds of more localized bodily feelings (e.g. the feeling of the hairs going up "on the neck" for fear), background feelings concern the sense of the body as a whole rather than of a specific part of it. But also if we conceive intentionality along the more standard meaning of "aboutness", then background feeling, with much more evidence, are not intentional either, because they can also be about anything-specific or a-specific - in the world (as I already showed in the $3^{\text {rd }}$ case of "tension”/“relaxation” example). In Goldie’s words, differently from bodily feelings arising from emotions, background feelings might also not "borrow" intentionality, even by the broader meaning of directedness to the world. Furthermore, if we conceive intentionality by the narrower sense as "aboutness", then we have to admit that background feelings are mainly "about" the body itself, rather, experienced as a whole.

In both Ratcliffe's and Goldie's understanding of intentionality it turns out that background feelings cannot be considered intentional or, at least, that their intentional content can be also anything at all in the world: The intentional content of background feelings, if any, turns out to be the body itself, perceived as a whole, rather ${ }^{29}$. As kinds of feelings that may also have no intentional reference to the world, background feelings clearly reveal their "pure" ${ }^{30}$ bodily core nature. Background feelings are kinds of feeling in which the bodily dimension and the intentional one (at least in the sense of reference to the world) are not necessarily connected. If we would like treating also background feelings as intentional states, then we would have to accept the body itself, considered as a whole, as their intentional content rather than the world.

In my opinion, then, intentional stance in the sense of world-reference rather pertains to the intentional states feelings concern, such as emotions, but also needs, motivations, desires, etc. (as felt states), but not to feeling "itself", which turns out to be completely bodily at its core. One might hypothesize, then, that feelings become intentional when dealing with intentional states, but feelings are not intentional by themselves. This common

\footnotetext{
${ }^{29}$ In an email correspondence (dated on $28^{\text {th }}$ April 2008) with the same Damasio about the intentionality of background feelings, so he answered to my question: "In general I agree with your interpretation. My caution, however, is that in a very broad sense even those states are intentional (in biological and philosophical meanings) because they are 'about' the regulation of body states albeit in a messy, somewhat inchoate way. As you know, I believe that even in single cells, without any brain or mind, 'mean' serious business when they regulate life so as to permit survival". By the way, this is not the meaning of intentionality we are discussing here. Between background feelings and the body there is an immediate, implicit, pre-noetic relation since when background feeling occur at the level of the unattended, unaware background-emotions level.

${ }^{30}$ In an email correspondence (dated on June 2011) with Gallagher he rejects this conclusion, maintaining that all bodily processes are "impurely" conditioned by the environment, in a theoretical frame considering an integrated brain-body-environment system. I don't believe in dis-embodied as in dis-embedded minds too, but this is not the point at issue here, I guess. What I want to underline is that, even in this structurally "intertwined" ontology, there is at least a boundary (that is the cutaneous surface-standardly considered the reference for the so-called "personal space" in the case of our own body, even if this is flexible and can be extended to a certain extent. About this, see Gallese \& Sinigaglia, 2011: 130-131) between body and environment, so that we can still distinguish our body from others’ or from environment in general-even if they do not exist isolated, of course. If not so, everything would be completely undistinguishable from another and we would live in a kind of "magmatic" reality with no differentiation between the others and us. This happens, in fact, just in the earliest phases of life of the infant, when he conceives no difference between himself and his mother (see Meltzoff \& Moore, 1977), or in severe psychosomatic pathologies (see Ulnik, 2005).
} 
feature of feelings might be revealed only by the "border case" of background feelings because, differently from other feelings, they neither arise from (proper) emotions nor from any other kind of intentional state (the so-called background "emotions" they follow, in fact, are not intentional either). In this kind of feelings the relation to the body, that is mostly on the "background" in bodily feelings connected to emotions, comes evidently in "foreground", in a way we can't realize in other feelings, always focused on an object or event (specific or a-specific) in the world.

Nevertheless, I do not argue that all feelings are only bodily and that they are not intentional at all: I claim that feelings, as revealed by the "border case" of background feelings, are themselves bodily at their core, but they become intentional when concerning intentional states such as emotions, needs, motivations, etc. In Goldie's words, but in a more radical sense, they "borrow" intentionality tout court (not only by the meaning of $d i-$ rectedness to the world beyond the body) when concerning intentional states such as emotions. Among feelings, only background feelings reveal this immediate, intimate connection to the body, we cannot realize in bodily feelings of intentional states like emotions, always referred to something in the world, they are mainly focused on. If we consider feeling always and only connected to the emotion-debate and also as being an intentional state itself, we might hardly understand what this kind of "immediate" access is, what is this relation to "ourselves" feelings nevertheless reveal, that is, at the end, a relation to our own body. We are usually unable to qualify this relation than metaphorically or in negative forms, such as "non linguistic", "non explicit" or as "pre reflective", "pre noetic" (Gallagher \& Zahavi, 2008) and so on, without any other further possible clarification. In this paper, I ought to contribute in paving the way towards a description of this relation to our body also in "positive" terms. In a nutshell, one might say, for ex., that this direct, unique relation to our own body as a whole, this kind of "immediate" access we all experience at different degrees of sensibility is realized by means of the complex collections of unaware physiological modifications occurring in our whole body. At a reflective level, background feelings themselves ("on-line", actualized aware perceptions of the state of the body, continuously updated) and more stable neural maps provided by proprioception and interocepion (maps of the "potential" state of the body) let the condition of the body as a whole - resulting from unaware, automatic bodily changes, occurring so to get homeostasis and staying "alive"-come to awareness ${ }^{31}$. My intuition is that this intimate relation to the bodybackground feelings reveal clearlier than other feelings_-should shed more light on another key feature of feelings, namely their phenomenality, more than their "supposed" intentionality.

But that's another story.

\section{Acknowledgements}

This paper is the main outcome of a research stay in Germany at IKW of Universitaet Osnabrueck, funded by the A. Von HUMBOLDT STIFTUNG, during the interdisciplinary research project "Animal emotionale I". I am in debt above all with Achim Stephan, who strongly helped and encouraged me in writing and publishing the paper. I also thank Shaun Gallagher for his punctual remarks and comments, Peter Goldie (to whose memory this paper is kindly dedicated, as kind as he was), and Matthew Ratcliffe for their attention to my work. I also acknowledge Ph.D. students and Postdoc of IKW research Centre in Osnabrueck (DE) and all the anonymous readers who discussed the paper with me in several informal situations.

\section{References}

Anderson, J. R. (1980). Cognitive Psychology and Its Implications. San Francisco: W. H. Freeman.

Barile, E. (2009). L’Ossimorodelle Rappresentazioni Neurali. Episteme, 3, 29-40.

Barile, E. (2010). Che Cosa Vuol Dire “Sentire”, "Provare” Qualcosa? Per unlessicodella vita affettiva fra fenomenologia e neuroscienze. Proceedings of Annual Meeting of the A. von Humboldt Stiftung, Italia. SLIFO, 8, 301-327.

Ben-Ze'ev, A. (2004). Emotion as a Subtle Mental State. In R. C. Solomon (Ed.) Thinking about Feeling: Contemporary Philosophers on Emotions (pp. 250-268). Oxford: Oxford University Press.

Brentano, F. (1874). Psychologie vom empirischen Standpunkt. Leipzig: Duncker \& Humblot.

\footnotetext{
${ }^{31}$ The more primitive level of "primordial feelings" (background feelings themselves develop from), whereas, require just wakefulness (granted by the brain stem integrity), not necessarily awareness. In line with recent approaches to phenomenal consciousness maintaining a kind of isomorphism in between phenomenality and the physiological dimension (see Marienberg \& Fingerhut (Eds.), 2012) Damasio sees in the brain stem systems interconnectivity a very first attempt to explain why these feelings “feel like” something (Damasio, 2010, 257).
} 
Cameron, G. et al. (2002). Visceral Sensory Neuroscience: Interoception. Oxford: Oxford University Press.

Castelfranchi, C. (1998). To Believe and to Feel: The case of “needs”. In D. Canamero (Ed.), Emotional and Intelligent: The tangled knot of cognition (pp. 55-60). Papers from the 1998 AAAI Fall Symposium. Menlo Park, CAL: AAAI Press.

Damasio, A. R. (1994). Descartes’ Error. Emotion, Reason and the Human Brain. New York: Quill. (Reprint)

Damasio, A. R. (1999). The Feeling of What Happens: Body and Emotion in the Making of Consciousness. New York: Harvest edition.

Damasio, A. R. (2003). Looking for Spinoza. Joy, Sorrow, and the Feeling Brain. Orlando: Harcourt.

Damasio, A. R. (2010). Self Comes to Mind. Constructing the Conscious Brain. New York: Pantheon Books.

Darwin, C. (1872). The Expression of Emotions in Man and Animals. London: Murray. http://dx.doi.org/10.1037/10001-000

De Monticelli, R. (2003). L'Ordinedel Cuore. Etica e teoriadelsentire. Milano: Garzanti.

De Sousa, R. (2009). Epistemic Feelings. Mind and Matter, 7, 139-161. (Reprint of 2008)

Deonna, J., \& Teroni, F. (2012). The Emotions: A Philosophical Introduction. London: Routledge.

Ekman, P. (2003). Emotion Revealed. London: Weidenfeld \& Nicolson.

Frijda, N. H. (1986). The Emotions. Cambridge: Cambridge University Press.

Gallagher, S. (2005). How the Body Shapes the Mind. Oxford: Oxford University Press. http://dx.doi.org/10.1093/0199271941.001.0001

Gallagher, S., \& Zahavi, D. (2008). The Phenomenological Mind. London: Routledge.

Gallese, V., \& Sinigaglia, C. (2011). How the Body in Action Shapes the Self. Journal of Consciousness Studies, 18, 117143.

Gilbert, M. (2002). Collective Guilt and Collective Guilt Feelings. The Journal of Ethics, 6, 115-143. http://dx.doi.org/10.1023/A:1015819615983

Goldie, P. (2000). The Emotions. A Philosophical Exploration. Oxford: Clarendon Press.

Goldie, P. (2002). Emotions, Feelings and Intentionality. Phenomenology and the Cognitive Sciences, 1, $235-254$. http://dx.doi.org/10.1023/A:1021306500055

James, W. (1884). What Is an Emotion? Mind, 9, 188-205. http://dx.doi.org/10.1093/mind/os-IX.34.188

Kosfeld, M., Heinrichs, M., Zak, P. J., Fischerbacher, U., Fehr, E. et al. (2005). Oxytocin Increases Trust in Humans. Nature, 435, 673-676. http://dx.doi.org/10.1038/nature03701

Kramer, P. D. (1993). Listening to Prozac: A Psychiatrist Explores Antidepressant Drugs and the Remaking of the Self. London: Penguin Books.

Lange, C. G. (1885). The Emotions. Baltimore, MD: William \& Wilkins.

Langer, S. (1942). Philosophy in a New Key: A Study in the Symbolism of Reasons, Rite and Art. Cambridge, MA: Harvard University Press.

LeDoux, J. E. (1996). The Emotional Brain: The Mysterious Underpinnings of Emotional Life. New York: Simon and Schuster.

Lenzen, W. (2004). Damasios Theorie der Emotionen. Facta Philosophica, 6, 269-309.

Marienberg, S., \& Fingerhut, J., Eds. (2012). The Feeling of Being Alive. Berlin: de Gruyter.

Meltzoff, A., \& Moore, M. K. (1977). Imitation of Facial and Manual Gestures by Human Neonates. Science, 198, 75-78. http://dx.doi.org/10.1126/science.198.4312.75

Merleau-Ponty, M. (1945). Phénoménologie de la Perception. Paris: Gallimard.

Nussbaum, M. (2001). Upheavals of Thought: The Intelligence of Emotions. Cambridge: Cambridge University Press. http://dx.doi.org/10.1017/CBO9780511840715

Ortony, A., Clore, G. L., \& Collins, A. (1988). The Cognitive Structure of Emotions. Cambridge: Cambridge University Press. http://dx.doi.org/10.1017/CBO9780511571299

Panksepp, J. (1998). Affective Neuroscience: The Foundation of Human and Animal Emotions. Oxford: Oxford University Press.

Ratcliffe, M. (2005). The Feeling of Being. Journal of Consciousness Studies, 12, 43-60.

Ratcliffe, M. (2012). The Phenomenology of Existential Feeling. In S. Marienberg, \& J. Fingerhut (Eds.), The Feeling of Being Alive (pp. 23-54). Berlin: de Gruyter.

Sacks, O. (1987). The Man Who Mistook His Wife for a Hat, and Other Clinical Tales. New York: Harper and Row. 
Schaffer, J. (1983). An Assessment of Emotion. American Philosophical Quarterly, 20, 161-173.

Scheler, M. (1913, 1916). Der Formalismus in der Ethik und die material Wertethik: Neuer Versuch der Grundlegung eines ethischen Personalismus. Bern: FranckeVerlag (1980), 340-351.

Searle, J. R. (1983). Intentionality. Cambridge: Cambridge University Press. http://dx.doi.org/10.1017/CBO9781139173452

Slaby, J. (2007). Affective Intentionality and the Feeling Body. Phenomenology and the Cognitive Sciences, 7, 429-444.

Slaby, J., \& Stephan, A. (2008). Affective Intentionality and Self-Consciousness. Consciousness and Cognition, 17, 506513. http://dx.doi.org/10.1016/j.concog.2008.03.007

Stern, D. (1985). The Interpersonal World of the Infant: A View from Psychoanalysis and Developmental Psychology. New York: Basic Books.

Stern, D. (2010). Forms of Vitality. Oxford: Oxford University Press.

Stocker, M. (1983). Psychic Feelings: Their Importance and Irreducibility. Australasian Journal of Philosophy, 61, 5-26. http://dx.doi.org/10.1080/00048408312349841

Tsakiris, M., \& Fotopoulou, A. (2008). Is My Body the Sum of Online and Offline Body Representations? Consciousness and Cognition, 17, 1317-1320. http://dx.doi.org/10.1016/j.concog.2008.06.012

Tsakiris, M., Prabhu, G., \& Haggard, P. (2006). Having a Body versus Moving Your Body: How Agency Structures Body-Ownership. Consciousness and Cognition, 15, 423-432. http://dx.doi.org/10.1016/j.concog.2005.09.004

Tsakiris, M., Schütz-Bosbach, S., \& Gallagher, S. (2007). On Agency and Body-Ownership: Phenomenological and Neurocognitive Reflections. Consciousness and Cognition, 16, 645-660. http://dx.doi.org/10.1016/j.concog.2007.05.012

Ulnik, J. (2005). El Psicoanálisis y la Piel. Madrid: Editorial Síntesis.

Yu, A. P., \& Dayan, P. (2005). Uncertainty, Neuromodulation, and Attention. Neuron, 46, 681-692. http://dx.doi.org/10.1016/j.neuron.2005.04.026 
Scientific Research Publishing (SCIRP) is one of the largest Open Access journal publishers. It is currently publishing more than 200 open access, online, peer-reviewed journals covering a wide range of academic disciplines. SCIRP serves the worldwide academic communities and contributes to the progress and application of science with its publication.

Other selected journals from SCIRP are listed as below. Submit your manuscript to us via either submit@scirp.org or Online Submission Portal.
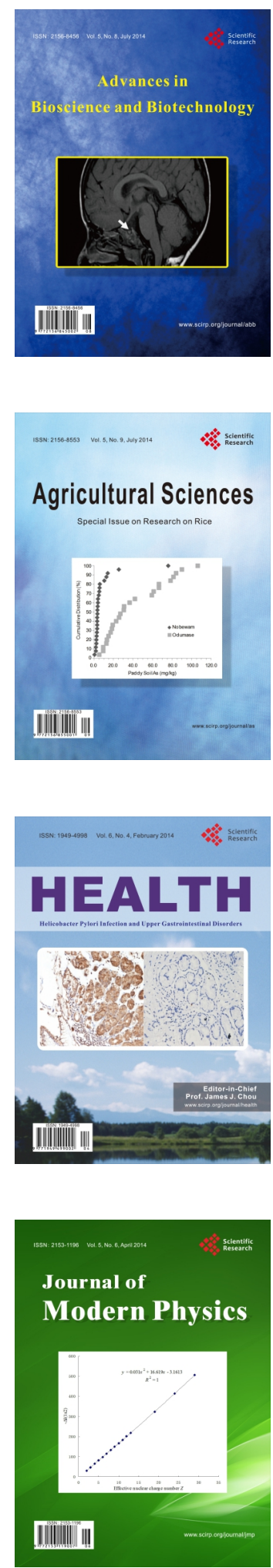
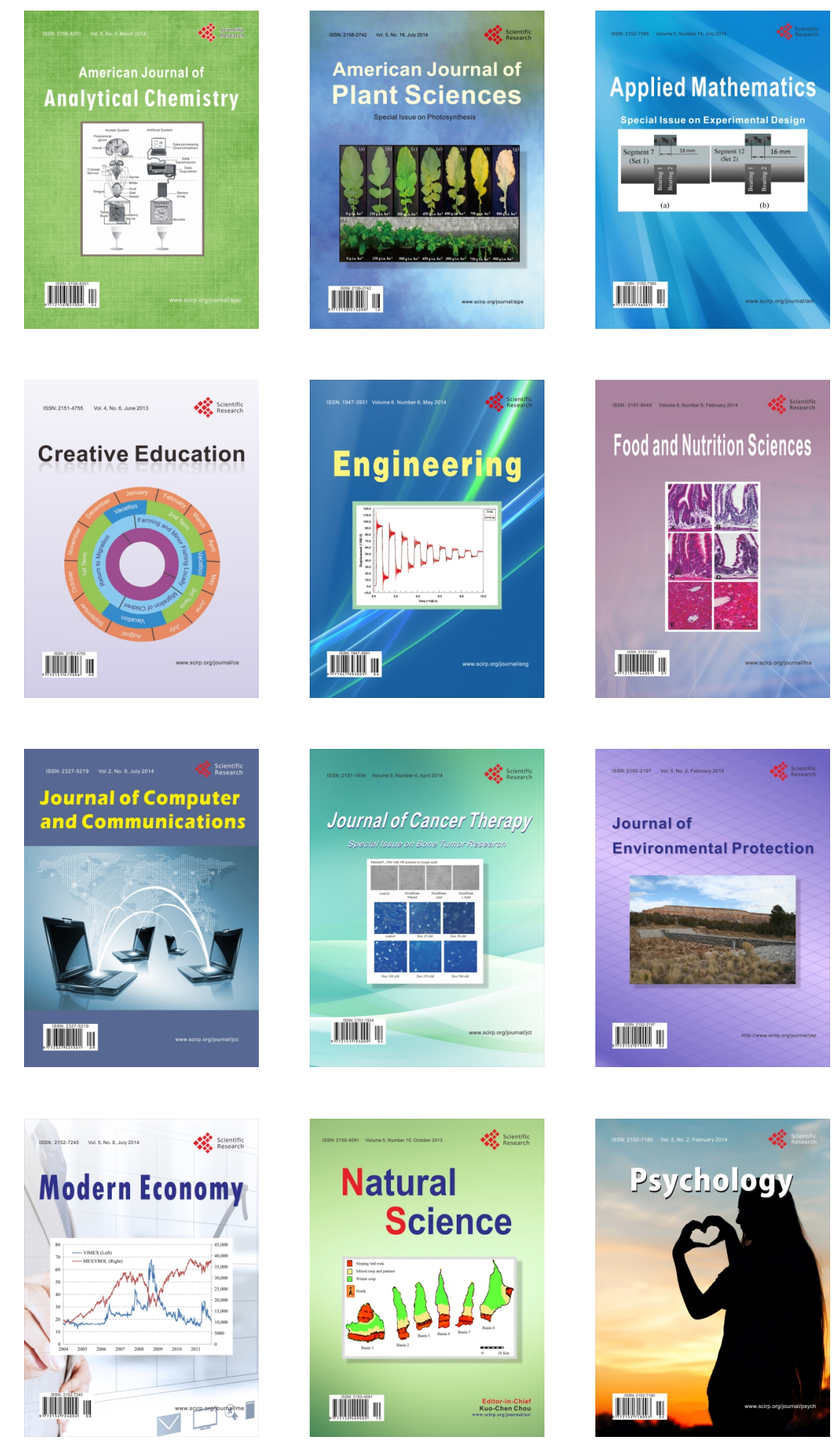